\title{
Enhancing positive development of children: Effects of a multilevel randomized controlled intervention on parenting and child problem behavior
}

\author{
Annette Cina ${ }^{\mathrm{a} *}$, Martin Röösli ${ }^{\mathrm{b}}$, Holger Schmid ${ }^{\mathrm{c}}$, Urs Peter Lattmannc, Barbara Fäh ${ }^{\mathrm{c}}$, Michaela Schönenberger ${ }^{\mathrm{c}}$, \\ Walter Kern-Scheffelt ${ }^{\mathrm{d}}$, Ashley K. Randall ${ }^{\mathrm{e}}$ and Guy Bodenmann ${ }^{\mathrm{f}}$ \\ ${ }^{a}$ University of Fribourg, Fribourg, Switzerland; ${ }^{b}$ Swiss Tropical and Public Health Institute, University of Basel, Basel, Switzerland; \\ ${ }^{c}$ University of Applied Sciences Northwestern Switzerland; ${ }^{d}$ Zurich University of Teacher Education, Zurich, Switzerland; ${ }^{e}$ University of \\ Arizona, Tucson, Arizona, USA; ${ }^{f}$ University of Zurich, Zurich, Switzerland
}

\begin{abstract}
Parent-oriented and school-oriented programs that aim to improve child behavior and mental health are well established, few studies focus on the possibility of additional benefits arising from a combined intervention. This study uses a randomized control trial and assesses whether the combination of two standardized evidence-based intervention programs, Triple $P$ (a self-directed parent-oriented intervention that focuses on strengthening parenting skills) and Fit and Strong for Life (a school-based intervention that focuses on stress management skills for children), was more likely to improve parenting and child behavior compared to either program alone and to a no-treatment control group. Data including pre- and post-test measures, as well as four- month follow-up data, were obtained from 78 teachers and 745 parents. Using linear mixed models, results showed that parents in the self-directed Triple $P$ condition engaged in less negative parenting behavior, more positive parenting strategies, scored lower on stress, and reported more parental self-efficacy at post-test. The effects remained at the four-month follow-up. Additionally, after treatment parents in the Triple P condition observed less behavioral problems in their child (although teachers did not). The Fit and Strong for Life intervention yielded no effects in respect to child problem behavior. Last, there was no additional benefit of the combined intervention group above that found for Triple P. This study encourages the utility, practicality, and efficacy of the self-directed Triple P Program and illustrates its effectiveness on positive parenting skills and problem child behavior.
\end{abstract}

Keywords: prevention; parenting; Triple P; self-competence training; children's well-being; school intervention

According to the World Health Organization (WHO), one out of five children has a mental or behavioral disorder (WHO, 2001). Findings suggest that psychological disorders often start in childhood (Costello, Mustillo, Erkanli, Keeler, \& Angold, 2006; Kessler et al., 2005; Kim-Cohen et al., 2003) and often persist until adulthood (Aguilar Sroufe, Egeland, \& Carlson, 2000; Hofstra, van der Ende, $\&$ Verhulst, 2002). Children with mental health and conduct problems show an increased likelihood for poor peer relationships, poor academic achievement, reduced selfesteem, and have a greater risk for substance abuse and delinquency (Loeber \& Farrington, 2001). Early implemented prevention can be considered a powerful tool in reducing the incident rates of mental health problems in children, and preventing negative development, such as drug abuse, delinquency, conduct problems and depression (WHO, 2004). Therefore, one can conclude that children are particularly susceptible to prevention and interventions focusing on these topics (Kim-Cohen et al., 2005).

Research on risk and protective factors shows that children's well-being and development is significantly associated with their familial environment (e.g., education) and social environment (e.g., peer relationships) when growing up (Cummings, Davies, \& Campbell, 2000; Dishion, Andrews, \& Crosby, 1995; Ivanova \& Israel, 2005; Loeber \& Farrington, 1998; Sameroff, 2000). In respect to the familial environment, a warm and supportive relationship with one's parents combined with adequate parenting (consistent and clear rules and structure) promotes positive physical and mental health, social integration, and school achievement (Coie, 1996; MacMillan et al., 1999; Morrow, 1999; Patterson, DeGarmo, \& Knutson, 2000; Rutter, 1996; Sanders \& Dadds, 1993; Webster-Stratton, 1993). The school context plays a crucial role for a child's development. Peer relationships are often associated with self-esteem, self-efficacy, a sense of control as well as social competences (Grotberg, 1996; Howard, Dryden, \& Johnson, 1999; Masten \& Reed, 2002; Rutter, 1990). Thus, given the importance of these two dimensions, prevention in the context of children might be best delivered in the family context, the school context, or even both (Benard, 1991). Programs that focus on parenting in the family context or on the training of social competence in the school context can be extremely successful in the prevention of behavioral problems, conduct problems and adjustment disorders as depression and anxiety (Gillham

*Corresponding author. Email: annette.cina@unifr.ch 
et al., 2006; Reid, 1993; Reivich, 2010; Webster-Stratton, Reid, \& Stoolmiller, 2008).

Effectiveness of interventions focusing on parenting skills are well proven (Petrie, Bunn, \& Byrne, 2007; Prinz \& Jones, 2003). Several meta-analyses report positive effects of parenting programs on parenting skills and/or child outcomes, such as the parent-child relationship, child-rearing skills, family functioning and emotional and behavioral adjustment of children (Barlow, Coren, \& Stewart-Brown, 2002; Lundahl, Nimer, \& Parsons, 2006). Programs such as the Incredible Years program (WebsterStratton, 1993) and the Triple P Positive Parenting Program (Markie-Dadds \& Sanders, 2006; Sanders, Markie-Dadds, Tully, \& Bor, 2000), have shown to be effective on positive outcomes such as improving parent-child interaction, strengthening effective emotional communication skills and emphasizing parenting consistency (Kaminski, Valle, Filene, \& Boyle, 2008).

In addition to parenting skills programs, skill-based programs for children have been developed and empirically tested for school settings. Many programs are based on Bandura's theory of self-efficacy (Bandura, 1994) or cognitive and social problem-solving according to the cognitive and emotional theory (Beck, 1976; Ellis, 1962). These skill-based programs focus on training social competence, problem-solving and anger management, and are often delivered in the school context. Programs as The Incredible Years: Parent, Teacher, Child Training Series (Webster-Stratton et al., 2001), the Penn Resiliency Project PRP (Gillham, Reivich, \& Jaycox, 2008) and Families and Schools Together (FAST) (Kratochwill, McDonald, Levin, Bear-Tibbetts, \& Demaray, 2004; Kratochwill, McDonald, Levin, Scalia, \& Coover, 2009) are examples of these skill-based programs that show good evidence. Their effectiveness has been proven with regard to positive social adjustment, reduction of health problems and improvement of self-esteem (Domitrovitch \& Grennberg, 2000; Elias, Gara, Schuyler, Brandon-Muller, \& Sayette, 1991; McConaughy, Kay, \& Fitzgerald, 1998; Wells, Barlow, \& Stewart-Brown, 2003; Young, Kelley, \& Denny, 1997).

Several programs focusing on prevention in the family environment or school setting are available in German. Among them is the Triple P-Positive Parenting Program, a widespread prevention and intervention program focusing on the enhancement of parenting skills of parents (Sanders, 1999). Triple $P$ is an evidence-based multilevel parenting and family support system for all parents (universal prevention) as well as specific groups (selective prevention) or parents confronting conduct problems of their child (indicated prevention).

The primary goal of Triple $P$ is to reduce the incidence of psychological disorders, behavioral problems, child abuse and delinquency in children and adolescents.
Triple $P$ is based upon social learning, cognitive-behavioral and developmental theories, and incorporates research on risk and protective factors associated with the development of social and behavioral problems in children (Sanders, 1999). The program aims to promote the independence and health of families by enhancing parents' knowledge on child rearing, parenting skills, and parentingrelated confidence. Triple $P$ focuses on: (a) basics of communication skills, reinforcement, monitoring, etiology of conduct disorders, goals of parenting and systematic behavior observation, (b) learning principles and promotion of healthy development, (c) strategies to deal with child problem behavior, parenting routines, and (d) plans of common activities and coping with situations at risk. Efficacy and effectiveness of Triple $P$ have been internationally demonstrated (e.g., de Graaf, Speetjens, Smit, de Wolff, \& Tavecchio, 2008; Markie-Dadds \& Sanders, 2006; Nowak \& Heinrichs, 2008; Sanders, Bor, \& Morawska, 2007).

As a school-oriented intervention the Fit and Strong for Life program is well established in Germany and Switzerland and previous evaluation studies of this program show good efficacy (Hanewinkel \& Assauer, 2003). Developed in Germany, "Fit and Strong for Life" prevents aggression, distress and addiction by improving personality development (Ahrens-Eipper, Asshauer, Burow, \& Weiglhofer, 2000; Asshauer, Burow, \& Hanewinkel, 1999; Burow, Asshauer, \& Hanewinkel, 1998). This program is based on a life skill approach (Botvin, 1998) and is supported by the WHO as a powerful tool for health promotion and prevention. In this program, six aspects of life competencies are trained: (1) introspection and empathy, (2) communication, (3) physical awareness and health relevant knowledge, (4) critical thinking, (5) coping with negative emotions/stress management, and (6) problem solving. The effectiveness of the program has been demonstrated in randomized controlled trials showing that students scored lower in aggressive behavior, depression/anxiety and social problems after participation in the program compared to control children (Hanewinkel \& Assauer, 2003).

\section{Current study}

Although parent-oriented and school-oriented training programs that use a single intervention have a positive impact on child well-being and problem behavior, some scholars suggest that multicomponent interventions directed at more than one risk domain show considerable promise in preventing conduct problems (Reid, Eddy, Fetrow, \& Stoolmiller, 1999; Webster-Stratton, Reid, \& Hammond, 2001), emotional health problems (Hosman, Jane-Llopis, \& Saxena, 2005) and substance abuse (Vakalahi, 2001). 
Rarely both environments are focused on simultaneously, except, for example, in The Incredible Years program (Webster-Stratton, Reid, \& Hammond, 2004), where parents, teacher and students receive support.

The present study evaluates the effectiveness of an intervention for parents (Triple $P$ ) compared to a schoolbased intervention for children (Fit and Strong for Life), a combined intervention (school-oriented intervention Fit and Strong for Life with the parent-oriented intervention Triple $($ ), and a waiting list control group in a randomized controlled trial to investigate what condition is most powerful in the change of child behavior. Additional effectiveness of the parent-oriented intervention on parenting factors such as parenting and parent well-being as important factors of child's behavior are also evaluated.

Hypotheses: We hypothesize that parent outcomes, such as parenting skills, well-being of parents, and life satisfaction, should show the most improvement in the parent-oriented intervention group (Triple $P$ ). We also hypothesize that changes in child's behavior will be most affected by the school-oriented intervention (Fit and Strong for Life), which focuses on life competencies, but also in an indirect way by the parent-oriented intervention (Triple $P$ ). Additionally, we assume that the combined intervention (Triple P and Fit and Strong for Life) will be most effective in reducing negative childhood behaviors, such as conduct problems, emotional problems, peer problems and improve pro-social behavior as both elements, direct and indirect interventions cumulate effects.

\section{Method \\ Recruitment}

Participants were recruited from primary schools in six cantons of the German-speaking area of Switzerland. During a period of four months, advertisements in the school newsletters provided information about the study and interested teachers received further information by mail $(\mathrm{N}=130)$. Out of the 130 interested teachers, 95 teachers took part in an information meeting, where information about the study, detailing exclusion and inclusion criteria and possible positive and negative effects were explained. In total, 95 teachers of 84 classes $(73 \%$ of the 130 teachers who received detailed information about the project) participated in this study. All participants completed an informed consent form and were responsible for the recruitment of children in their class and their parents. All parents whose child was in a class of participating teachers received information on the study and were asked to participate by the teacher during an informative meeting. From 1466 eligible parents, 948 participated in these meetings and 904 (64\%) signed informed consent for participating in the study.

\section{Participants}

Complete data from 528 parents and reports of 73 teachers were finally available and statistical analyses are based on this sample size. Parents $(N=528)$. A majority of the parents participating in the study were of Swiss nationality $(79 \%)$ and female $(N=88.7 \%)$. The mean age of the parents was 40.1 years $(S D=4.9)$. Most of the parents were living with their partner (89\%) and were married (86\%). The mean duration of their relationship was 11.9 years $(S D=4.6)$. On average they had 2.3 children (range: $1-4)$, aged between 3 to 23 years. With respect to education, $14 \%$ of the parents had finished primary school, $48 \%$ high school, 20\% college, and 18\% had attended university. Participation rate was higher in Swiss parents $(66.3 \%$ of potentially available parents) than in parents with another ethnic background ( $19.5 \%$ of potentially available parents). The mean age of the index child (parent reports) in the survey was 8.7 years $(S D=1.7)$, with $46.4 \%$ of the children being girls and $53.6 \%$ boys.

Teachers $(N=73)$. Teachers participating in the study were on average 45.4 years old $(S D=10.67)$ and in majority female $(77 \%)$. There were no significant differences between groups in demographic characteristics, except for educational level of the parents (higher-educated parents in the control group condition compared to the intervention group 1, school-oriented intervention, Fit and Strong for Life, and the intervention group 2, parent-oriented intervention, Triple P. Full participation at all three surveys (full attended sample) was similar for families with a boy $(72.5 \%)$ or a girl $(70.2 \%)$, but somewhat higher for mothers $(72.3 \%)$ than fathers $(55.8 \%)$ and for Swiss parents $(74.7 \%)$ compared to parents with another ethnic background (56.4\%).

\section{Procedures}

The school classes were assigned via computer-generated randomization to the four intervention conditions. The teachers and parents were randomly assigned to one of the four groups. The computer-based randomization assigned 24 classes (teachers with their students and their parents) to the school-based intervention Fit and Strong for Life (group 1), 20 classes to the parent-oriented intervention Triple $P$ (group 2), 20 classes to the combined intervention (Fit and Strong for Life and Triple P; group 3) and 21 classes to the waiting list control group (group 4). Before completing the study, seven teachers dropped out of the study.

The questionnaires were sent per mail to the parents at home and to the teachers at school. Parents completed questionnaires at home while teachers did so in the school. If more than one child per family was in the same class participating in the study, the parents (either mother or father depending on who was most involved in child rearing) completed the set of questionnaires for each child 
separately. Questionnaires were administered at three times of measurement: pre-measurement (two weeks prior to the intervention), post-measurement (two weeks after completion of the intervention), and follow-up measurement (four months after completion of the intervention).

At pretest, data from 771 parents $(52.6 \%$ of all eligible parents) and from 78 teachers could be collected.
Between pretest and follow-up, 243 parents refused to continue or did not complete the questionnaires. At the follow-up complete data over all measurements were available from 528 parents (36\% of all eligible parents, $68.5 \%$ of the parents starting with the program) and 73 teachers $(93.6 \%$ of teachers starting with the program).

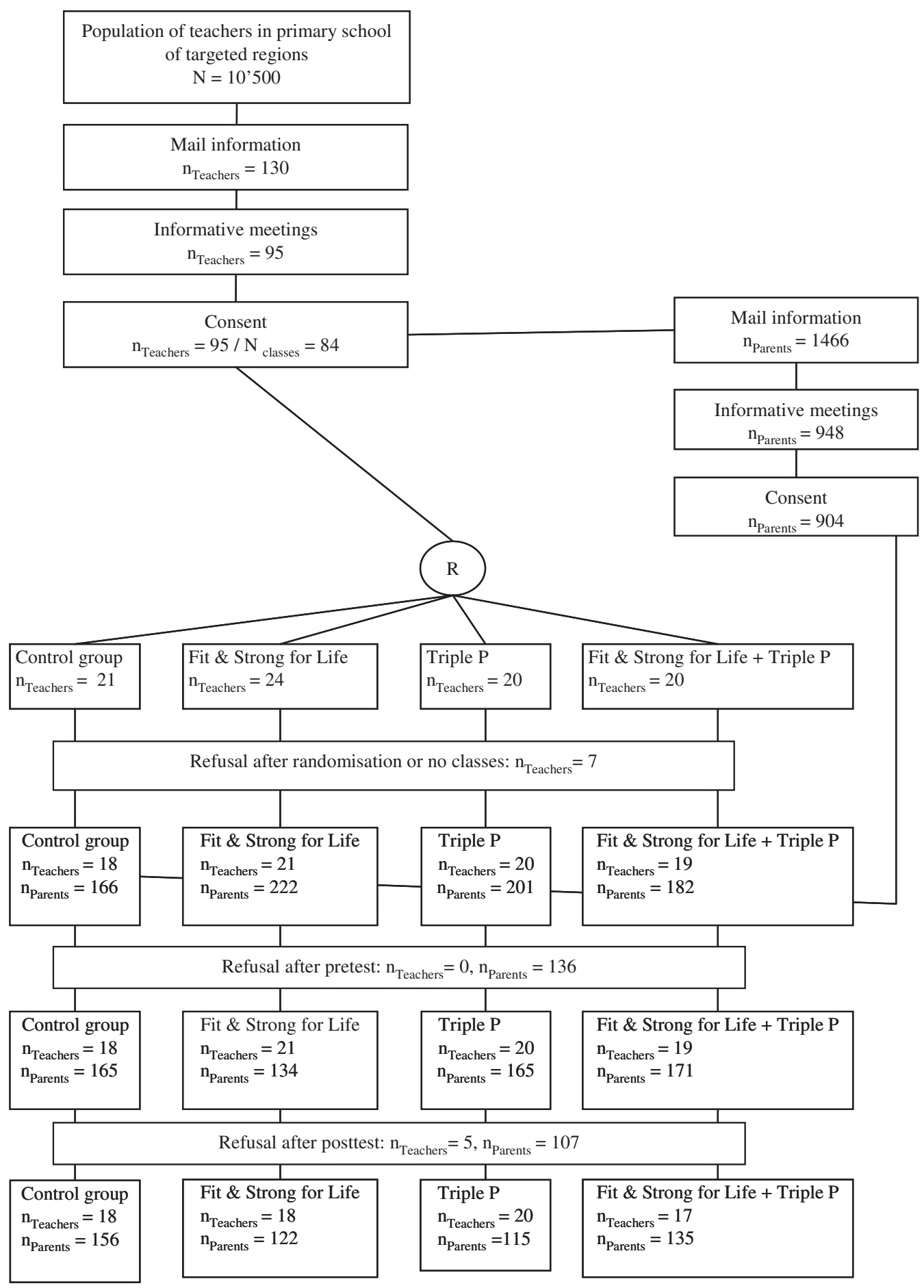

Figure 1. Consort flow chart. 


\section{Intervention programs}

The parent-oriented intervention: Self-directed Triple P

From the entire Triple P multilevel intervention system, the self-directed Triple P Program was chosen. Self-directed Triple $\mathrm{P}$ is designed for families wanting to work through the program at home. Parents received the Triple $P$ selfhelp workbook and the DVD "Every Parent's Survival Guide". The workbook guides parents through a 10-week series of reading and practicing tasks to help them deal with the demands of caring for, supervising, educating and managing their children. Each week also includes additional recommended resource materials. The DVD demonstrates specific parenting strategies and supports the reading. Additionally, parents were supported by 10 weekly telephone calls lasting between 20 and 30 minutes duration with trained Triple $\mathrm{P}$ providers who coached the parents in technical as well as practical questions. The program was delivered in five languages such as German, English, Albanian, Portuguese and Turkish, representing the biggest language groups in the Swiss German part of Switzerland.

Intervention adherence was controlled by weekly telephone calls by trained Triple $P$ providers. The mean completion of telephone calls was 6.9 (12.4\% $1-4$ sessions, $19.4 \%$ 5-6 sessions, $68.2 \%$ seven or more sessions). Additionally, parents reported for each telephone call if the session was helpful for them, if the provider was competent and responsive using a 5 point scale $(1=$ not at all to $5=$ very). Of all telephone calls $85.8 \%$ were rated to be helpful $(55.8 \%)$ to very helpful $(30 \%)$. Only $1.5 \%$ of the calls were reported to be not helpful. In general, the providers were rated to be competent or very competent $(86.4 \%)$ and responsive or very responsive $(88.4 \%)$.

The school-oriented intervention: "Fit and Strong for Life" (Fit und stark fuers Leben)

The school-oriented program "Fit and Strong for Life" was chosen for our study. Prior to the implementation, the teachers were trained in conducting the program at school. Over 12 to 14 weeks teachers conducted the program in their class and trained their students during weekly 60 - to 90 -minute sessions according to the manual in the life competencies. In order to facilitate skill acquisition, modeling was practiced by introducing two hedgehogs (Igor and his friend Isabella) that show children how they can deal more effectively with difficulties, stress and social tensions. Exercises to improve behaviors, attitudes and emotion regulation are the core elements of each unit. In order to guarantee high treatment adherence, "Fit and Strong for Life" was delivered in a standardized format during school time with a manualized protocol.

\section{Measures}

\section{Parent questionnaires}

Sociodemographic variables. A range of sociodemographic information was collected, including the age and sex of children and parents, parents' employment status, education levels, marital status, annual household income, and ethnic background.

The Positive Parenting Questionnaire (PPQ) is a 13item measure that is based on the Parenting Practise Scale (Strayhorn \& Weidman, 1988). Positive, supporting and reinforcing parenting behaviors are assessed on a 4-point scale $(0=$ "never" to $3=$ "very often"). The reliability of the measure is $\operatorname{good}(\alpha=.81)$.

Parenting Scale (PS; Arnold, O'Leary, Wolff, \& Acker, 1993). A shortened version of the PS including 13 items was used to measure parents' dysfunctional discipline styles on two subscales: laxness (permissive discipline) and over-reactivity (authoritarian discipline, displays of anger, meanness, and irritability). These two scales constitute the total score and both were rated on a 7-point scale. The PS is used to discriminate between clinical and non-clinical levels of dysfunctional parenting. In the present study, the internal consistencies of the scales were adequate (PS laxness $\alpha=.81$; PS over-reactivity $\alpha=.77$; PS total $\alpha=.74)$.

Problem Setting and Behavior Checklist (PSBC; Sanders \& Woolley, 2005) is a 28-item scale that assesses how confident parents are in dealing with child behavior problems in various settings. It uses a 4-point scale with 1 $=$ "I cannot manage the problem very well" to $4=$ "I can manage the problem very well". The scale showed a high internal consistency $(\alpha=.95)$ in this study.

Depression Anxiety Stress Scale (DASS; Lovibond \& Lovibond, 1995). The DASS is a 42-item measure aimed to assess symptoms of depression, anxiety, and stress in adults on a 4-point scale from $0=$ "did not apply to me at all" to $3=$ "applied to me very much or most of time." The scale measures the extent to which each state has been experienced over the past week and showed high reliability for Depression $(\alpha=.87)$, Anxiety $(\alpha=.65)$ and Stress $(\alpha=82)$. The total scale demonstrated high internal consistency $(\alpha=.90)$.

Resilience Scale (RS-11; Schumacher, Leppert, Gunzelmann, Strauss, \& Brähler, 2005) is the short German version of the Resilience Scale from Wagnild and Young (1993). The 11-item measurement assesses resilience on a 7-point scale from $1=$ "I do not agree" to 7 = "I do agree" (sample item: "I feel that I can handle many things at a time"). The scale showed a high internal consistency $(\alpha=.95)$.

Life satisfaction $(L S)$ is a 5-item scale measuring life satisfaction on a 5-point scale from $1=$ "not at all" to $5=$ "very" that has been developed by our research team. Items assess how much subjects are happy with life conditions, how much they feel satisfied with their life, how much they 
perceive problems in their life, how much they think that others have a better life, and how much their life conditions match expectancies. The internal consistency of the scale was high $(\alpha=.95)$.

\section{Child outcome variables}

The Strengths and Difficulties Questionnaire (SDQ; Goodman, 1997) was used by parents and teachers to assess the nature and extent of children's emotional and behavioral problems as reported by parents and by teachers. There are 25 items in the SDQ with each subscale consisting of five items. The SDQ yields a total problem score that is generated by summing the scores from all scales except the prosocial scale. The SDQ also yields a score on the emotional subscale, the conduct subscale, the hyperactivity subscale, peer problems subscale, and the prosocial subscale. Scores on the SDQ can also be classified as normal, borderline and abnormal. The SDQ is a widely used measure of children's mental health problems. Various psychometric studies have shown it to have good internal consistency and test retest reliability (Goodman, 1997). The internal consistency of the scale was high $(\alpha=.91)$.

\section{Statistical analyses}

The effectiveness of the different interventions was tested using a baseline/post-test and follow-up control group design. Data were analyzed using linear mixed models accounting for clustering by a random intercept effect at the class level. For each item score, the difference between the post and the baseline measurement was calculated, as well as the difference between the follow-up and the baseline measurement. For each of these differences a linear mixed regression analysis using the type of intervention as an explanatory variable was computed. The control group was used as a reference group.

Sensitivity analyses were performed by controlling in all our models for potential confounding factors and effect modifiers such as child's age, gender, nationality, family type and number of siblings as well as age and gender of the person that completed the questionnaire. All analyses were performed with STATA 9.0.

\section{Results}

\section{Effects of interventions on parental outcomes}

Post intervention effects. Parental outcomes as positive parenting, dysfunctional parenting and parenting confidence improved significantly after the intervention (postmeasurement) in the Triple $P$ and the combined group (Triple $P$ and Fit and Strong for Life) compared to the control group (see Table 1); however, no significant effect was found in the Fit and Strong for Life group (see Table 2). The increase in the PPQ score (positive parenting) in the Triple $P$ group was 0.19 (95\% CI: $0.12-0.26)$ units higher than in the control group between post and baseline. Similarly, the reduction of the PS total score (dysfunctional parenting) in the Triple $P$ condition was -0.34 (95\% CI: -0.52 to -0.17 ) units between post and baseline compared to the control group, primarily basing on a reduction of over reactivity in parenting situations $(b=-0.66,95 \% \mathrm{CI}:-0.87$ to $-0.45)$. Accordingly parents report a significant improvement in confidence of dealing with problem child behaviors (PSBC score: $b=0.25,95 \%, \mathrm{CI}: 0.16-0.34$ ), and report smaller depression levels (DASS depression score: $b=$ $-0.15,95 \%$, CI: -0.25 to -.04 ) and less stress (DASS stress score: $b=-0.27,95 \%, \mathrm{CI}:-0.42$ to -0.13$)$. They also feel more resilient in coping with daily challenges $(b=$ $0.24,95 \%$, CI: $0.4-0.45)$. Similar changes were observed in the combined group, where effects were comparable.

Follow-up intervention effects. The results of the follow-up measurement (four months after the intervention) match these findings on improved parenting, although effect sizes were lower. After four months, parents of the Triple $P$ group reported better parenting strategies (positive parenting score PPQ: $b=0.14,95 \%$, CI: $0.06-$ 0.22 ; dysfunctional parenting PS: $b=-0.24,95 \%$, CI: -0.39 to -0.9 mainly less over reactivity: $b=-0.43,95 \%$, CI: -0.64 to -0.21 ) and a stronger confidence in dealing child problem behavior (PSBC score: $b=0.23,95 \%, \mathrm{CI}$ : $0.14-0.31)$. Not stable over four months are the effects of the well-being scales: The effects are weaker (DASS total score: $b=-0.11,95 \%, \mathrm{CI}$ : -0.20 to -0.02 ; DASS depression score: $b=-0.11,95 \%$, CI: $-0.22-0.01$, DASS stress score: $b=-0.17,95 \%$, CI: -0.31 to -0.03$)$ and not significant any more for the resiliency scale.

The changes in the combined group were similar with respect to the parenting scales. They report positive effects on the dysfunctional parenting in an equal effect range (PS score: $b=-0.21,95 \%, \mathrm{CI}:-0.36$ to -0.06$)$, but the effect on the positive parenting was scored less high (PPQ score: $b=0.07,95 \%, \mathrm{CI}:-0.01-0.15)$. With regard to the wellbeing scales, the parents of the combined group report less stress (DASS stress score. $b=-0.16,95 \%, \mathrm{CI}:-0.30$ to -0.01 ), but report better resiliency (RS score: $b=0.26$, 95\%, CI: $0.8-0.45$ ) and life satisfaction (LS score: $b=$ $0.15,95 \%$, CI: $0.03-0.28)$. No change on their well-being and parenting was reported by the parents of the Fit and Strong for Life group. Adjusting the analysis for potential confounders (sex and age of the index child, amount of siblings, nationality, living facility, parent relationship duration, and parent's school grade) did not significantly change the effect estimates (data not shown in order to limit pages).

\section{Effects of interventions on child behavior}

As reported above, child behavior was rated by parents and teachers. Table 3 shows the mean and the standard deviation of the SDQ strength and difficulty scores for baseline, post and follow-up measurements. 


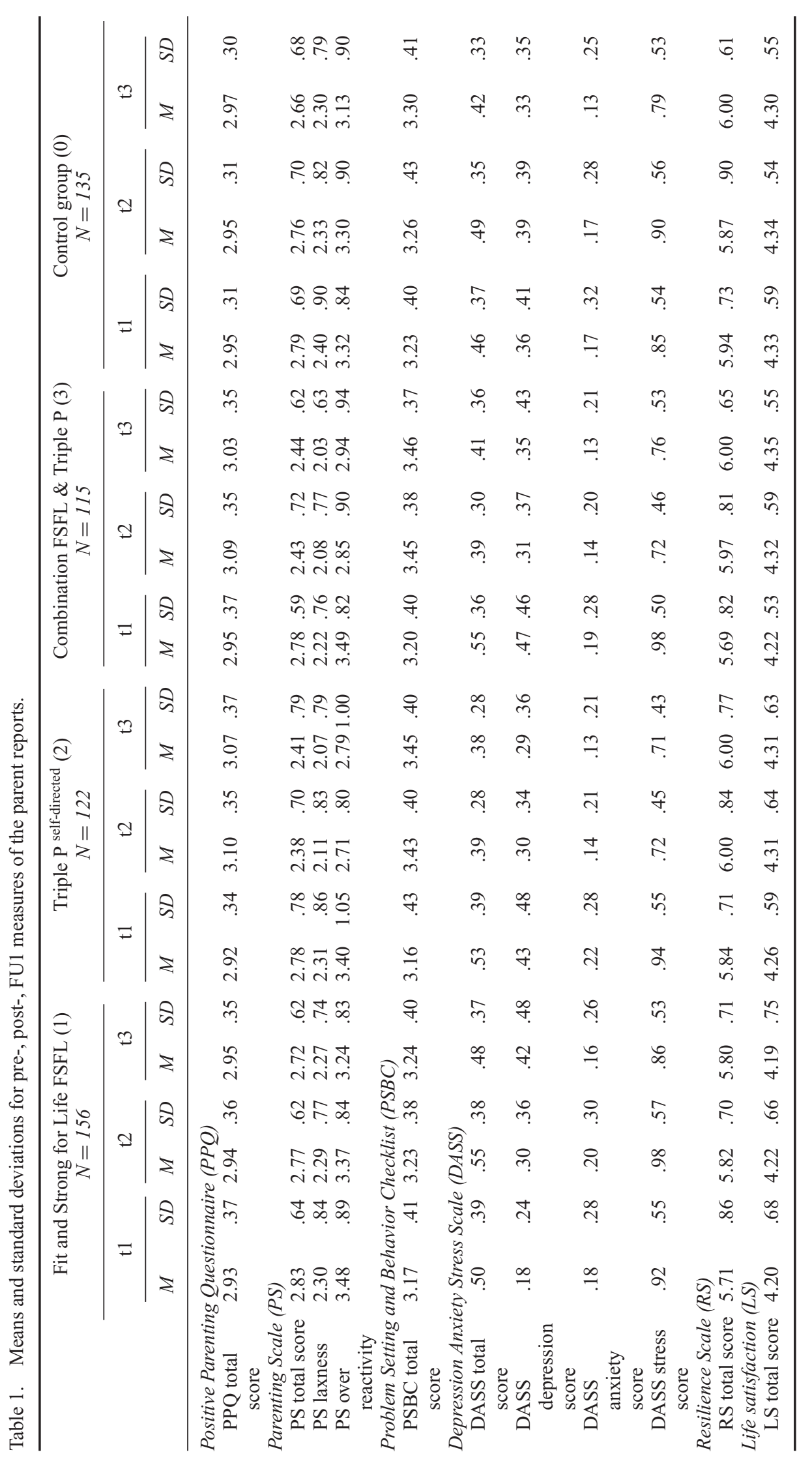




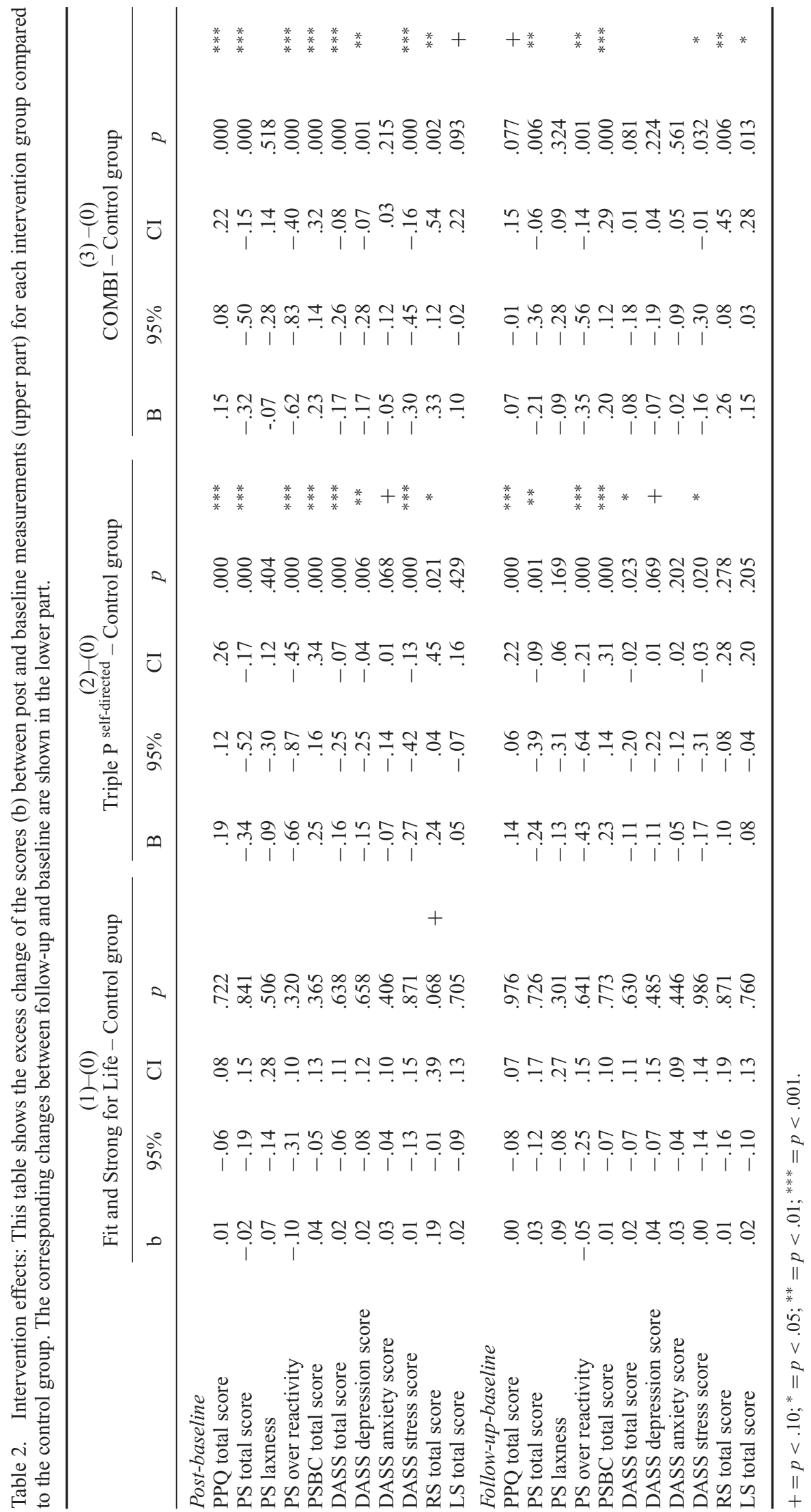




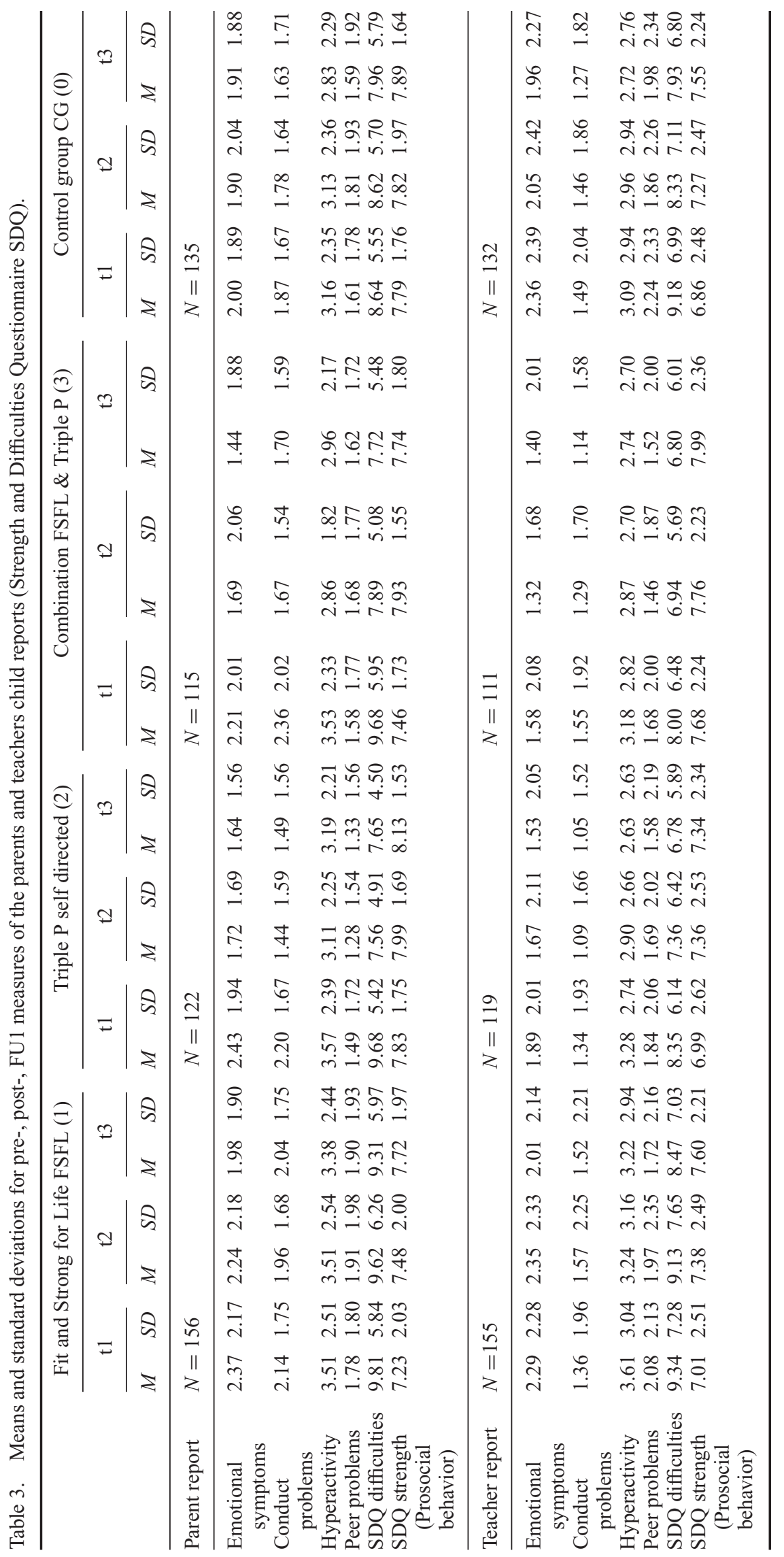




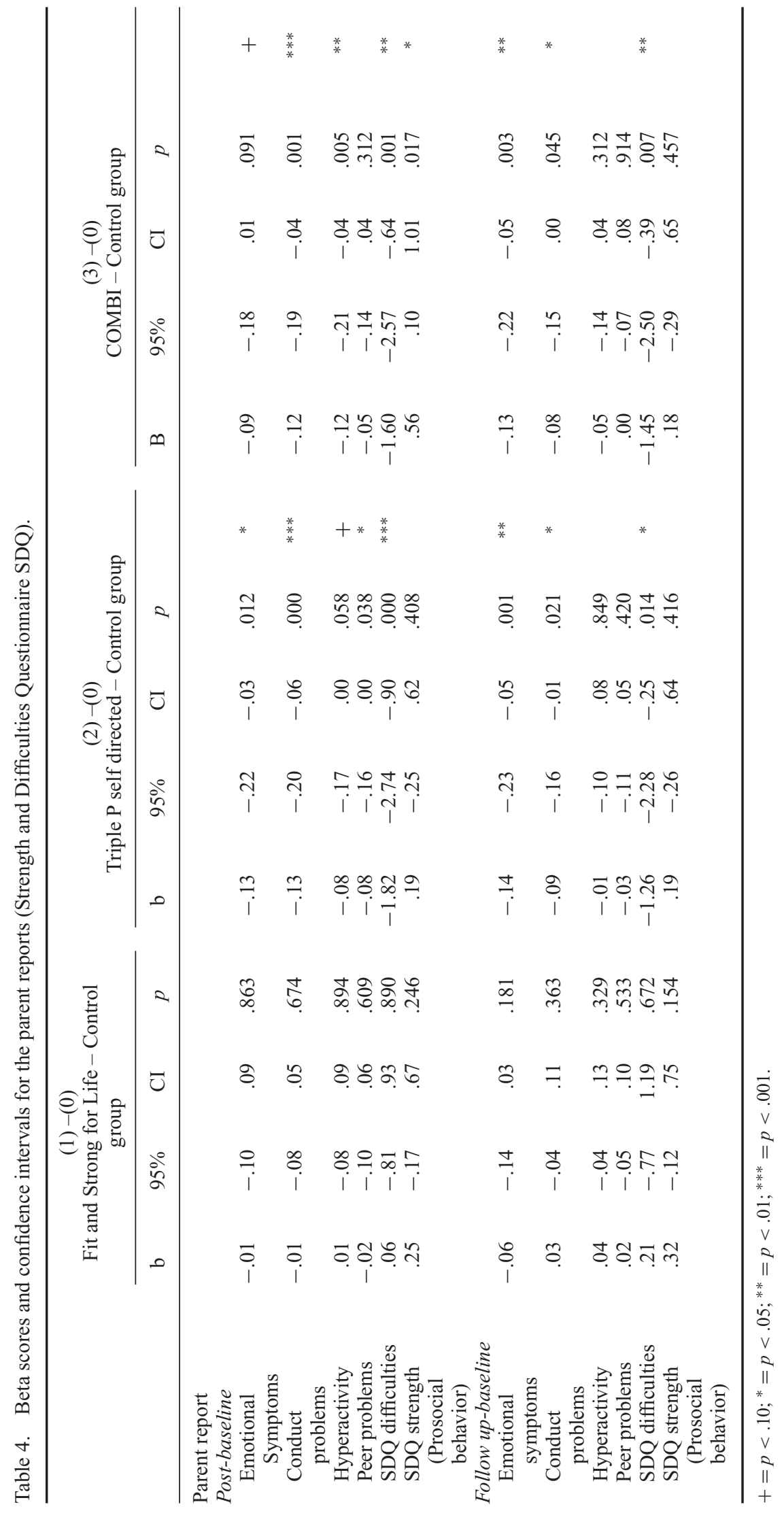


Post intervention effects. According to the parental assessment, the SDQ difficulty score in the Triple $P$ and the combined group decreased significantly after the intervention compared to the baseline measurements (Table 4). Compared to the control group, the reduction of difficult child behavior in the Triple $P$ group was $b=-1.82(95 \%$ CI: -2.74 to -0.90$)$. The parents observed less conduct problems, less emotional problems, peer-related problems and less hyperactivity symptoms on their child. Parents did not report differential changes on prosocial behavior, however. Parents of the combined intervention group reported similar effects, although they did notice a positive change in the child's prosocial behavior ( $b=0.56,95 \%$, CI: 0.10 1.01). No change in the child's behavior was noticed by parents of the Fit and Strong for Life intervention group.

According to the teachers' assessment, the SDQ strength and difficulty scores did not change in any of the intervention groups (see Table 5).

Follow-up intervention effects. Four months after the intervention, the effect of the intervention was still significant for reduction of child problem behavior, but less pronounced according to the parent reports at post assessment (see Table 4). Parents of the Triple $P$ group and combined intervention group reported less child behavior difficulties (Triple $P$ group: $b=-1.26,95 \%, \mathrm{CI}:-2.28$ to 0.25 ; combined intervention group: $b=-1.45,95 \%$, CI: -2.50 to -0.39 ). These effects are based on reduced emotional problem symptoms (Triple $P$ group: $b=-0.14$, $95 \%, \mathrm{CI}:-0.23$ to 0.05 ; combined intervention group: $b=$ $-0.13,95 \%$, CI: -0.22 to -0.05$)$ and conduct problems (Triple $P$ group: $b=-0.09,95 \%, \mathrm{CI}:-0.16$ to $0.01 ; \mathrm{com}$ bined intervention group: $b=-0.08,95 \%, \mathrm{CI}:-0.15$ to 0.00 ). No effect on the prosocial behavior was reported by the parents four month after intervention.

No change in the child's behavior was observed by parents of the Fit and Strong for Life intervention group and by teachers of all groups, except of teachers of the Fit and Strong for Life intervention group which report by trend more conduct problem behavior of the children $(b=0.09$, 95\%, CI: $-0.01-0.19)$ (see Table 5).

\section{Discussion}

This study used 528 parents (primarily mothers) and 78 teachers ( 80 school classes) to examine the effects of prevention programs (Triple $P$ and Fit and Strong for Life) on parenting and changes in child behavior. This study not only evaluated outcomes of in-home interventions, but the school context as well; therefore, it differs from many previous studies where self-selected samples with children showing behavioral problems or emotional distress were examined. Our results showed that after participating in the Triple $P$ program, parents reported an improvement in their positive parenting practices, a decrease in their negative parenting practices (less overreacting, more

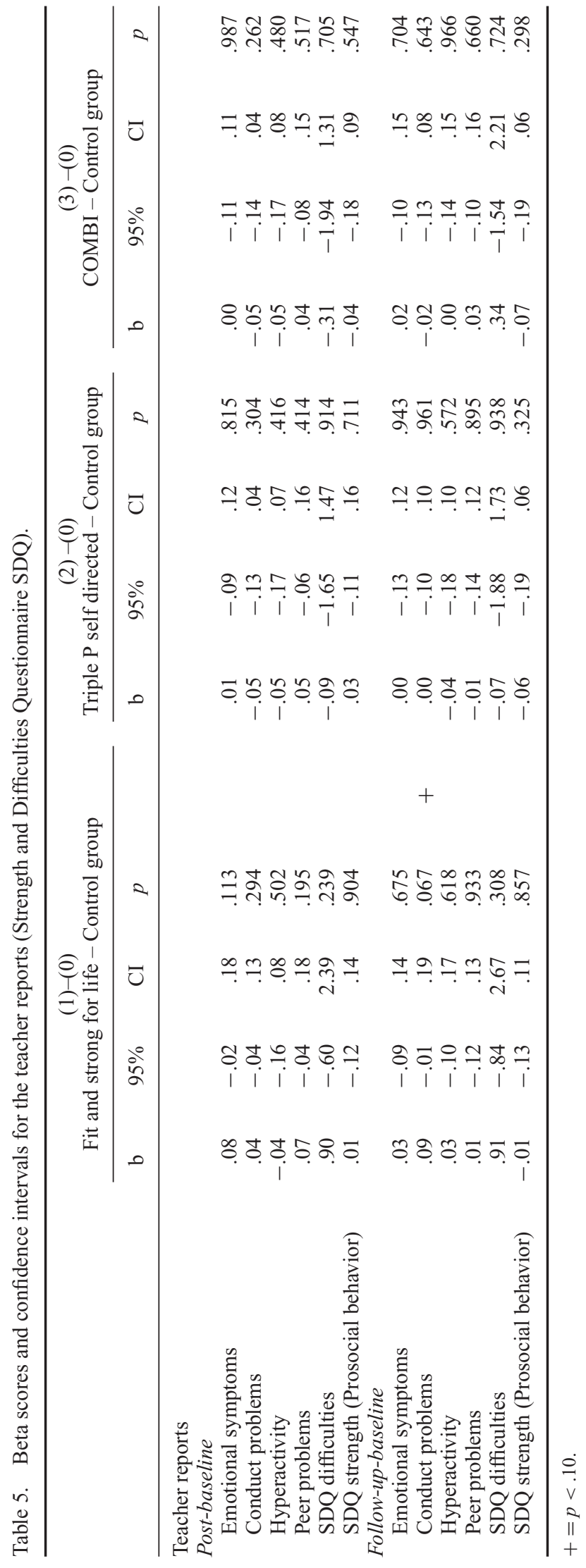


self-confidence in dealing with child problem behavior). Positive effects on the parents, such as their wellbeing and resilience were stable over four months in the combined intervention group, but not in the single Triple $P$ intervention group. Furthermore, significant effects on child outcome variables (i.e., reduction of behavioral difficulties but no improvement of strengths) were reported by parents who attended the Triple $P$ intervention, although no changes on the child's behavior were observed by the teachers.

The results support previous findings on the efficacy of Triple $P$ in various international studies (e.g., Bodenmann, Cina, Ledermann, \& Sanders, 2008; Heinrichs et al., 2006; Leung, Sanders, Leung, Mak, \& Lau, 2003; Sanders, 1999; Sanders et al., 2007; Sanders \& Dadds, 1993). Additionally, de Graaf et al. (2008) in a meta analysis showed that Triple $P$ is an effective method for strengthening parenting competencies and for improving children's behavior and well-being yielding within-group effect sizes of $d=$ .55 to 1.46 and between-group effect sizes of $d=.50$ to 1.27 (for post and follow-up measurements up to one year). Furthermore, our findings support the effectiveness of selfdirected Triple $P$ (Markie-Dadds \& Sanders, 2006; Sanders et al., 2000) indicating that this approach may be as efficacious as the group program format and is helpful for families (Serketich \& Dumas, 1996).

Based on our study, Triple $P$ has an effect in the family and not in other contexts such as school. The results support previous observations by Taylor and Biglan (1998) that assume that effects of parent-oriented training programs often do not spill-over to the school setting or are not as readily perceived by teachers as by parents. We believe there are a few factors that may explain the discrepancy in parent and teacher ratings. First, parents, especially mothers, may be more vigilant observers of their child's behavior and are able to more accurately detect behavior changes, compared to teachers that work with numerous children and have fewer opportunities to closely monitor one child's behavior. Secondly, difficult child behavior may not necessarily occur in both settings, which could account for the discrepancy of ratings in parents and teachers.

While findings on Triple $P$ were compatible with previous finding, the school-oriented program Fit and Strong for Life did not show the expected effects, as no significant impact of this intervention on children's behavior was found. The study yields contradictory effects to previously reported strengths of this approach (Ahrens-Eipper et al., 2000; Asshauer et al., 1999; Burow et al., 1998).

Contrary to our hypotheses, the combined intervention (Triple P and Fit and Strong for Life) did not have a much greater impact on children's behavior than Triple $P$ alone. Thus, the assumption that multilevel-interventions combining different levels (parent-oriented, school-oriented, etc.) should be more successful than single interventions (Dishion \& Kavanagh, 2000; Hosman et al., 2005; Miller et al., 1998; Vakalahi, 2001) was not supported by our data. However, given that the Fit and Strong for Life intervention did not have an effect in the single intervention group, a cumulative effect of a combined intervention might still be found when a more rigorous school intervention program is used.

Overall, our findings suggest evidence-based preventive interventions such as Triple $P$ are valuable methods to enhance child behavior in the family setting without further interventions. Notably, the results of self-directed Triple $P$, a less intensive version of Triple $P$ than the group format for parents, suggested this intervention was effective, and this is encouraging for several reasons. First, it suggests that self-directed programs could be as effective as time consuming and costly intensive workshops. Second, this mode of delivery could be considered more convenient, and supports lower economical costs. Third, self-directed training may increase the likelihood of participation of families with low income, low time resources, or greater geographical distance, as the self-delivery of the program may increase participation in those that are not willing to participate in "traditional" programs offered outside the home. Thus, this approach allows for greater reach to families with minimal investment, compared to parent workshops.

\section{Limitations}

Despite our significant results, we acknowledge some limitations to the current study. One limitation concerns the parental ratings, as our results mostly relied on the mother's reports on child behavior, as the families were only given one questionnaire per family. The decision to only include one parent in this study was based on two major decisions. First, we wanted the parents to define who would fill in the questionnaire, but this also allowed for the opportunity to both parents complete the questionnaire together. In our study, a majority of parent participants were mothers. Second, as parents were coached by telephone contacts, we decided to only work with one parent and not both parents for logistical reasons. It would have been too ambitious and time consuming to call mothers and father of 745 families knowing that often several calls will be necessary to reach both parents.

Another constraint is that in this article only the effects of parents and teachers who completed the questionnaires at all measurement points were included $(68 \%$ of the parents and $96 \%$ of the teachers starting in the study). Therefore effects can be confirmed for parents who fully attended the study.

Another limitation of this study is that no additional observations were made by clinicians (psychiatrics, psychologists, psychotherapists) and only parents and teachers' report were included (children's data were not presented in this article). There could be a bias in the parents' reports as they completed the parenting training. 
Additionally, in respect to the time frame of the study, effects of the treatments were only analyzed within a time-frame of four months, thus we have no information about long-term effects of the interventions. Despite these limitations, we believe that this study does contribute to a better understanding of universal prevention in parents and schools but we are also convinced that further studies are needed to foster this knowledge. As child behavioral disorders are a common phenomenon, universal prevention programs are important and knowledge on their efficacy is needed.

\section{Conclusions and future directions}

In summary, our results encourage the utility, practicality and efficacy of self-directed programs for parents (selfdirected Triple P), and illustrate that parent-oriented interventions are effective in reducing child behavior problems. The study did not support the extra benefit of the additional school-oriented program Fit and Strong for Life, although several authors point out the need and value of such programs (Hosman et al., 2005). Family variables such as parenting, parental stress, and parenting self-efficacy are powerful predictors of child outcomes (Aviezer, SagiSchwartz, \& Koren-Karie, 2003; Erel \& Burman, 1995; Grych \& Fincham, 1990; Loeber \& Farrington, 1998; Spence, 1998) and targeting these factors is promising for intervention. Empirical findings on widespread universal prevention campaigns in childhood and adolescence are still sparse, but merit further attention, particularly selfdirected programs (e.g., Hahlweg, Heinrichs, Kuschel, \& Feldmann, 2008; Sanders et al., 2000).

\section{References}

Aguilar, B., Sroufe, L.A., Egeland, B., \& Carlson, E. (2000). Distinguishing the early-onset/persistent and adolescenceonset antisocial behaviour types: From birth to sixteen years. Development and Psychopathology, 12, 109-132.

Ahrens-Eipper, S., Asshauer, M., Burow, F., \& Weiglhofer, H. (2000). Fit und Stark fürs Leben. 5. und 6. Schuljahr. Prävention des Rauchens durch Persönlichkeitsförderung [Fit and Strong for Life. 5th and 6th school year. Smoke prevention trough strengthening personality]. Leipzig: Ernst Klett Grundschulverlag.

Arnold, D.S., O’Leary, S.G., Wolff, L.S., \& Acker, M.M. (1993). The parenting scale: A measure of dysfunctional parenting in discipline strategies. Psychological Assessment, 5, 137-144.

Asshauer, M., Burow, F., \& Hanewinkel, R. (1999). Fit und Stark fürs Leben. Persönlichkeitsförderung zur Prävention von Aggression, Stress und Sucht (Band 3. und 4. Schuljahr) [Fit and Strong for Life. Strengthening personality for prevention of aggression, stress and addiction (3rd and 4th school year)]. Leipzig: Ernst Klett Grundschulverlag.

Aviezer, O., Sagi-Schwartz, A., \& Koren-Karie (2003). Ecological constraints on the formation of infant - mother attachment relations: When maternal sensitivity becomes ineffective. Infant Behavior and Development, 26, 285-299.
Bandura, A. (1994). Self-efficacy. In V.S. Ramachaudran (Ed.), Encyclopedia of human behaviour (Vol. 4, pp. 71-81). New York: Academic Press.

Barlow, J., Coren, E., \& Stewart-Brown, S. (2002). Meta-analysis of the effectiveness of parenting programmes in improving maternal psychosocial health. British Journal of General Practice, 52, 223-233.

Beck, A.T. (1976). Cognitive therapy and the emotional disorders. New York: International Universities Press.

Benard, B. (1991). Fostering resiliency in kids: Protective factors in the family, school, and community. San Francisco: Far West Laboratory for Educational Research and Development.

Bodenmann, G., Cina, A., Ledermann, T., \& Sanders, M.R. (2008). The efficacy of Positive Parenting Program (Triple P) in improving parenting and child behavior: A comparison with two other treatment conditions. Behavior Research and Therapy, 46, 411-427.

Botvin, G.J. (1998). Re adolescent drug abuse through life skills training. Theory, methods and effectiveness. In J. Crane (Ed.), Social programs that really work (pp. 225-257). New York: Sage.

Burow, F., Asshauer, M., \& Hanewinkel, R. (1998). Fit und stark fürs Leben 1. und 2. Schuljahr. Persönlichkeitsförderung zur Prävention von Aggression, Rauchen und Sucht [Fit and Strong for Life. 1st and 2nd school year. Strengthening personality for prevention of aggression, smoking and addiction]. Leipzig: Ernst Klett Grundschulverlag.

Coie, J.D. (1996). Prevention of violence and antisocial behavior. In R. Peters \& R.J. McMahon (Eds.), Preventing childhood disorders, substance abuse, and delinquency (pp. 1-18). Thousand Oaks, CA: Sage.

Costello, E.J., Mustillo, S., Erkanli, A., Keeler, G., \& Angold, A. (2006). Prevalence and development of psychiatric disorders in childhood and adolescence. Archives of General Psychiatry, 60, 837-844.

Cummings, E.M., Davies, P.T., \& Campbell, S.B. (2000). Developmental psychopathology and family process: Theory, research, and clinical implications. New York: The Guilford Press.

de Graaf, I., Speetjens, P., Smit, F., de Wolff, M., \& Tavecchio, L. (2008). Effectiveness of the Triple P Positive Parenting Program on parenting: A meta-analysis. Family Relations, 57, 553-566.

Dishion, T.J., Andrews, D.W., \& Crosby, L. (1995). Antisocial boys and their friends in early adolescence: Relationship characteristics, quality and interactional process, Child Development, 66(1), 139-151.

Dishion, T.J., \& Kavanagh, K. (2000). A multilevel approach to family-centered prevention in schools: process and outcome. Addictive Behaviors, 25, 889-911.

Domitrovitch, C.E., \& Greenberg, M.T. (2000). The study of implementation: Current findings from effective programs that prevent mental disorders in school-aged children. Journal of Educational and Psychological Consultation, 11, 193-221.

Elias, M.J., Gara, M.A., Schuyler, T.F., Brandon-Muller, L.R., \& Sayette, M. (1991). The promotion of social competence: Longitudinal study of a preventive schoolbased program. American Journal of Orthopsychiatry, 61, 409-417.

Ellis, A. (1962). Reason and emotion in psychotherapy. New York: LyIe Stuart.

Erel, O., \& Burman, B. (1995). Interrelatedness of marital relations and parent-child relations: A meta-analytic review. Psychological Bulletin, 118, 108-132.

Gillham, J.E., Reivich, K.J., Freres, D.R., Lascher, M., Litzinger, S., Shatté, A., et al. (2006). School-based prevention of 
depression and anxiety symptoms in early adolescence: A pilot of a parent intervention component. School Psychology Quarterly, 21, 323-348.

Gillham, J.E., Reivich, K.J., \& Jaycox, L.H. (2008). The Penn Resiliency Program. Unpublished manuscript, University of Pennsylvania.

Goodman, R. (1997). The Strengths and Difficulties Questionnaire: A research note. Journal of Child Psychology and Psychiatry and Allied Disciplines, 38, 581-586.

Grotberg, E.H. (1996). The international resilience project: Findings from the research and effectiveness of intervention. Annual Convention of the International Council of Psychologists, Banff, Canada.

Grych, J.H., \& Fincham, F.D. (1990). Marital conflict and Children's Adjustment: A cognitive-contextual framework. Psychological Bulletin, 108, 267-290.

Hahlweg, K., Heinrichs, N., Kuschel, A., \& Feldmann, M. (2008). Therapist-assisted, self-administered bibliotherapy to enhance parental competence: Short- and long-term effects. Behavior Modification, 32(5), 659-681.

Hanewinkel, R., \& Assauer, M. (2003). "Fit und stark fürs Leben". Universelle Prävention des Rauchens durch Vermittlung psychosozialer Kompetenzen [Fit and Strong for Life. Universal prevention of smoking through enhancing psychosocial skills]. Suchttherapie, 4, 197-199.

Heinrichs, N., Hahlweg, K., Bertram, H., Kuschel, A., Naumann, S., \& Harstick, S. (2006). Die langfristige Wirksamkeit eines Elterntrainings zur universellen Prävention kindlicher Verhaltensstörungen: Ergebnisse aus Sicht der Mütter und Väter [The long-term effectiveness of parent training for universal prevention of child behavior problems]. Zeitschrift für Klinische Psychologie und Psychotherapie, 35, 82-96.

Hofstra, M.B., van der Ende, J., \& Verhulst, F.C. (2002). Child and adolescent problems predict DSM-IV disorders in adulthood: A 14-year follow-up of a Dutch epidemiological sample. Journal of the American Academy of Child and Adolescent Psychiatry, 41, 182-189.

Hosman, C., Jane-Llopis, E., \& Saxena, S. (Eds). (2005). Prevention of mental disorders: Effective interventions and policy options. Oxford: Oxford University Press.

Howard, S., Dryden, J., \& Johnson, B. (1999). Childhood resilience: Review and critique of the literature. Oxford Review of Education, 25, 307-323.

Ivanova, M.Y., \& Israel, A.C. (2005). Family stability as a protective factor against the influences of pessimistic attributional style on depression. Cognitive Therapy and Research, 29(2), 243-251.

Kaminski, J.W., Valle, L.A., Filene, J.H., \& Boyle, C.L. (2008). A meta-analytic review of components associated with parent training program effectiveness. Journal of Abnormal Child Psychology, 36, 567-589.

Kessler, R.C., Berglund, P., Demler, O., Jin, R., Merikangas, K.R., \& Walters, E.E. (2005). Lifetime prevalence and age-of-onset distributions of DSM-IV disorders in the National Comorbidity Survey replication. Archives of General Psychiatry, 62, 593-602.

Kim-Cohen, J., Arseneault, L., Caspi, A., Tomas, M.P., Taylor, A., \& Moffitt, T.E. (2005). Validity of DSM-IV conduct disorder in 4.5-5-year-old children: A longitudinal epidemiological study. American Journal of Psychiatry, 162, 1108-1117.

Kim-Cohen, J., Caspi, A., Moffitt, T.E., Harrington, H., Milne, B.J., \& Poulton, R. (2003). Prior juvenile diagnoses in adults with mental disorder, developmental follow-back of a prospective-longitudinal cohort. Archives of General Psychiatry, 60, 709-717.
Kratochwill, T.R., McDonald, L., Levin, J.R., Bear-Tibbetts, H.Y., \& Demaray, M.K. (2004). Families and schools together: An experimental analysis of a parent-mediated multi-family group program for American Indian children. Journal of School Psychology, 42, 359-383.

Kratochwill, T.R., McDonald, L., Levin, J.R., Scalia, P.A., \& Coover G. (2009). Families and schools together: An experimental study of multi-family support groups for children at risk. Journal of School Psychology, 47, 245-265.

Leung, C., Sanders, M.R., Leung, S., Mak, R., \& Lau, J. (2003). Outcome evaluation of the implementation of the Triple P Positive Parenting Program in Hong Kong. Family Process, 22. Retrieved December, from http://www.findarticles.com/p/articles/mi_m0AZV/is_4_42/ ai_113182900.

Loeber, R., \& Farrington, D.P. (1998). Never too early, never too late: Risk factors and successful interventions for serious violent juvenile offenders. Studies on Crime and Crime Prevention, 7, 7-30.

Loeber, R., \& Farrington, D.P. (Eds.). (2001). Child delinquents: Development, intervention and service needs. Thousand Oaks, CA: Sage.

Lovibond, S.H., \& Lovibond, P.F. (1995). Manual for the Depression Anxiety Stress Scales (2nd ed.). Sydney: Psychology Foundation.

Lundahl, B.W., Nimer, J., \& Parsons, B. (2006). Preventing child abuse: A meta-analysis of parent training programs. Research on Social Work Practice, 16, 251-262.

MacMillan, H.L., Boyle, M.H., Wong, M.Y.Y., Duku, E.K., Fleming, J.E., \& Walsh, C.A. (1999). Slapping and spanking in childhood and its association with lifetime prevalence of psychiatric disorders in a general population sample. Canadian Medical Association Journal, 161, 805-809.

Markie-Dadds, C., \& Sanders, M.R. (2006). Self-Directed Triple P (Positive Parenting Program) for mothers with children at-risk of developing conduct problems. Behavioural and Cognitive Psychotherapy, 34, 259-275.

Masten, A.S., \& Reed, M.G.J. (2002). Resilience in development. In C.R. Snyder \& S.J. Lopez (Eds.), Handbook of positive psychology (pp. 74-88). New York: Oxford University Press.

McConaughy, S.H., Kay, P.J., \& Fitzgerald, M. (1998). Preventing SED through parent-teacher action research and social skills instruction: First year outcomes. Journal of Emotional and Behavioral Disorders, 6, 81-93.

Nowak, C., \& Heinrichs, N. (2008). A comprehensive metaanalysis of Triple P - Positive Parenting Program using hierarchical linear modeling: Effectiveness and moderating variables. Clinical Child and Family Psychology Review, 11, 114-144.

Patterson, G.R., DeGarmo, D.S., \& Knutson, N. (2000). Hyperactive and antisocial behaviors: Comorbid or two points in the same process? Development and Psychopathology, 12, 91-106.

Petrie, J., Bunn, F., \& Byrne, G. (2007). Parenting programmes for preventing tobacco, alcohol or drugs abuse in children under 18: A systematic review. Health Education Research, $22,177-191$.

Prinz, R.J., \& Jones, T.L. (2003). Family-based interventions. In C.A. Essau (Ed.), Conduct and oppositional defiant disorders: Epidemiology, risk factors, and treatment (pp. 279-298). Mahwah, NJ: Erlbaum.

Reid, J.B. (1993). Prevention of conduct disorder before and after school entry: Relating interventions to developmental findings. Development and Psychopathology, 5, 243-262. 
Reid, J.B., Eddy, J.M., Fetrow, R.A., \& Stoolmiller, M. (1999). Description and immediate impacts of a preventive intervention for conduct problems. American Journal of Community Psychology, 24, 483-517.

Reivich, K. (2010). Building resilience in youth: The Penn resiliency program. National Association of School Psychologists. Communique. Retrieved March 2011 from http://www.faqs.org/periodicals/201003/2030175571.html

Rutter, M. (1990). Psychosocial resilience and protective mechanisms. In J. Rolf, A. Masten, D. Cicchetti, K. Nuechterlein, \& S. Weintraub (Eds.), Risk and protective factors in the development of psychopathology (pp. 181-214). New York: Cambridge University Press.

Rutter, M. (1996). Developmental psychopathology: Concepts and prospect. In M.F. Lenzenweger \& J.J. Haugaartd (Eds.), Frontiers of developmental psychopathology (pp. 209-237). New York: Oxford University Press.

Sameroff, A. (2000). Ecological perspectives on developmental risk. In J.D. Osofsky \& H.E. Fitzgerald (Ed.), Handbook of infant mental health: Infant mental health in groups at high risk (Vol. 4, pp. 1-337). New York: Wiley.

Sanders, M.R. (1999). The Triple P-Positive Parenting Program: Towards an empirically validated multilevel parenting and family support strategy for the prevention of behavior and emotional problems in children. Clinical Child and Family Psychology Review, 2, 71-90.

Sanders, M.R., Bor, W., \& Morawska, A. (2007). Long term maintenance effects of three variants of the Triple P-Positive Parenting Program for early onset conduct problems. Journal of Abnormal Child Psychology, 35, 983-998.

Sanders, M.R., \& Dadds, M.R. (1993). Behavioral family intervention. Needham Heights, MA: Allyn and Bacon.

Sanders, M.R., Markie-Dadds, C., Tully, L., \& Bor, B. (2000). The Triple P- Positive Parenting Program: A comparison of enhanced, standard and self-directed behavioural family intervention for parents of children with early onset conduct problems, Journal of Consulting and Clinical Psychology, 68, 624-640.

Sanders, M.R., \& Woolley, M.L. (2005). The relationship between maternal self-efficacy and parenting practices: Implications for parent training child. Care, Health and Development, 31, 65-73.

Schumacher, J., Leppert, K., Gunzelmann, T., Strauss, B., \& Brähler, E. (2005). Die Resilienzskala - Ein Fragebogen zur Erfassung der psychischen Widerstandsfähigkeit als Personmerkmal [The Resilience Scale: Questionnaire for the assessment of mental strength as a person characteristic]. Zeitschrift für Klinische Psychologie, Psychiatrie und Psychotherapie, 53, 16-39.

Serketich, W.J., \& Dumas, J.E. (1996). The effectiveness of behavioural parent training to modify antisocial behaviour in children: A meta-analysis. Behaviour Therapy, 27, 171-186.

Spence, S.H. (1998). Preventive interventions. In T.H. Ollendick (Ed.), Comprehensive Clinical Psychological
Vol. 5. Children \& Adolescents: Clinical Formulation and Treatment (pp. 295-315). Amsterdam, New York: Elsevier, Pergamon.

Strayhorn, J.M., \& Weidman, C.S. (1988). A parent practices scale and its relation to parent and child mental health. Journal of the American Academy of Child and Adolescent Psychiatry, 27, 613-618.

Taylor, T.K., \& Biglan, A. (1998). Behavioral family interventions for improving child rearing: A review for clinicians and policy makers. Clinical Child and Family Psychology Review, 1, $41-60$.

Vakalahi, H.F. (2001). Adolescent substance use and family-based risk and protective factors: A literature review. Journal of Drug Education, 31, 29-46.

Wagnild, G.M., \& Young, H.M. (1993). Development and psychometric evaluation of the Resilience Scale. Journal of Nursing Measurement, 1, 165-178.

Webster-Stratton, C. (1993). Strategies for helping families with young oppositional defiant or conduct-disordered children: The importance of home and school collaboration. School Psychology Review, 22, 437-457.

Webster-Stratton, C., Mihalic, S., Fagan, A., Arnold, D., Taylor, T., \& Tingley, C. (2001). Blueprints for violence prevention, book eleven: The incredible years: Parent, teacher and child training series. Boulder, CO: Center for the Study and Prevention of Violence.

Webster-Stratton, C., Reid, M.J., \& Hammond, M. (2001). Preventing conduct problems, promoting social competence: A parent and teacher training partnership in Head Start. Journal of Clinical Child Psychology, 30, 283-302.

Webster-Stratton, C., Reid, J.M., \& Hammond, M. (2004). Treating children with early-onset conduct problems: Intervention outcomes for parent, child, and teacher training. Journal of Clinical Child and Adolescent Psychology, 33, 105-124.

Webster-Stratton, C., Reid, J.M., \& Stoolmiller, M. (2008). Preventing conduct problems and improving school readiness: Evaluation of the incredible years teacher and child training programs in high-risk schools. Journal of Child Psychology an Psychiatry, 49, 471-488.

Wells, J., Barlow, J., \& Stewart-Brown, S. (2003). A systematic review of universal approaches to mental health promotion in schools. Health Education, 103(4), 197-220.

WHO. (2001). The world health report 2001: Mental health: New understanding, new hope. Geneva: World Health Organization.

WHO. (2004). Summary report: Prevention of mental disorders - effective interventions and policy options. Geneva: World Health Organization.

Young, M., Kelley, R., \& Denny, G. (1997). Evaluation of selected life-skills modules from the contemporary health series with students in Grade 6. Perceptual and Motor Skills, 84, 811-818. 